\title{
CONSULTORIA INTERNA EM GESTÃO DE PESSOAS: A CHAVE PARA A ATUAÇÃO ESTRATÉGICA DA ÁREA
}

\section{INTERNAL CONSULTING IN HUMAN RESOURCES MANAGEMENT: THE KEY TO STRATEGIC ACTION

\section{Júlio Fernando da Silva ${ }^{1}$}

Recebido em: 23/12/2016 Aceito em: 27/09/2017

juliofs02@hotmail.com
Resumo: O presente ensaio tem como objetivo compreender como a consultoria interna em gestão de pessoas contribui para a atuação da gestão estratégica de pessoas. Por meio da revisão de literatura, constata-se que o modelo de consultoria interna incorporado às estratégias e práticas de gestão de pessoas possibilita o alinhamento entre as pessoas e a estratégia corporativa, favorecendo a comunicação nas equipes e na própria organização. Ademais, as pesquisas empíricas sobre o tema revelam algumas evidências que podem estar diretamente relacionadas ao sucesso do modelo de consultoria interna, sendo elas: a preparação do consultor interno, do gestor, da alta administração, e posteriormente de toda a organização. Para o desenvolvimento de futuras pesquisas sugerem-se alguns aspectos teóricos oportunos para legitimação empírica.

Palavras-chave: Consultoria interna em gestão de pessoas. Gestão estratégica de pessoas. Alinhamento estratégico.

Abstract: The essay aims to understand how the internal consulting in human resources management contributes to the performance of human resources strategic management. Through the review of literature, it appears that the internal consulting model incorporated into strategies and human resources management practices enables alignment between the people and the corporate strategy, facilitating communication in the teams and in the organization itself. In addition, the empirical research on the subject reveals some evidences that can be directly related to the success of the internal consulting model, being: the preparation of the internal consultant, the manager, the top management, and later of the whole organization. For the development of future research, it is suggested some opportune theoretical aspects for empirical legitimation.

Keywords: Volunteering. Motivation. Volunteer motivation.

\footnotetext{
${ }^{1}$ Pontifícia Universidade Católica de Minas Gerais - PUC Minas - Belo Horizonte - Minas Gerais - Brasil.
} 


\section{INTRODUÇÂO}

O ambiente empresarial vem se tornando cada vez mais competitivo e dinâmico, desafiando as organizações a desenvolverem mecanismos capazes de potencializar suas competências corporativas e garantir que os indivíduos estejam comprometidos com os resultados organizacionais (VENTURA; LEITE, 2014). Tais padrões competitivos de mercado exigem das organizações novas estratégias focadas na melhoria contínua, na otimização dos custos e na busca por inovações e vantagens competitivas sustentáveis (SILVEIRA; MAESTRO FILHO, 2013).

Diante desse cenário, a função da área de gestão de pessoas passou a ser considerada um elemento estratégico, na medida em que tem assumido papéis e práticas mais relacionadas à esfera estratégica das organizações (MASCARENHAS, 2011). Assim, o ser humano passou a ser considerado o ator principal na realização dos propósitos organizacionais, cabendo à gestão estratégica de pessoas alinhar e compartilhar os interesses dos indivíduos aos interesses da organização, bem como impulsionar esforços e comprometimento do comportamento humano para o alcance dos objetivos empresariais (VENTURA; SILVA, 2014).

Em busca de uma atuação estratégica, a área de gestão de pessoas tem passado por diversos caminhos, abordando como fatores, a descentralização da gestão de pessoas para as lideranças, os códigos de ética e conduta, a implantação de políticas corporativas de $\mathrm{RH}$, entre outros. A fim de romper com a estrutura historicamente formatada em um modelo funcional, a gestão de pessoas tem utilizado o modelo de consultoria interna, sendo implantado em empresas nacionais e internacionais (ALBERTON; MANCIA; BORBA, 2009).

Tal modelo de consultoria interna proporciona mais agilidade nos processos de gestão de pessoas, diante da visão fragmentada e departamental das organizações, ampliando a atuação da área na busca constante por conhecimento e inovação (GIRARDI; LAPOLLI; TOSTA, 2009). Ademais, refere-se a um modelo de apoio a gestão, que envolve uma mudança na estrutura e nos processos de $\mathrm{RH}$, no qual os consultores apoiam a prática da gestão de pessoas na empresa, por meio de diagnósticos, intervenções e suporte às lideranças para tomadas de decisão (ALBERTON; MANCIA; BORBA, 2009).

Assim, o presente ensaio tem como objetivo compreender como a consultoria interna em gestão de pessoas contribui para a atuação da gestão estratégica de pessoas. A base para realização do estudo deu-se pela investigação na literatura mediante o que os principais autores desse campo destacam sobre tal contribuição, dentre eles Ulrich (1998), Alberton, Mancia e Borba (2009), Girardi, Lapolli e Tosta (2009), Leite e Albuquerque (2009), Leite et al. (2009), Caparajó e Lira (2010), Mascarenhas (2011), Orlickas (2013) e Silva (2013), e também das pesquisas empíricas publicadas em nível nacional.

Após esta introdução, apresenta-se o aporte teórico acerca dos conceitos da consultoria interna em gestão de pessoas e as pesquisas empíricas sobre o tema, as características da gestão estratégica de pessoas, e a contribuição da consultoria interna em gestão de pessoas para a atuação estratégica da área. Posteriormente são apresentadas as considerações finais do estudo.

Estudos do CEPE [ISSN 1982-6729]. Santa Cruz do Sul, n. 46, p. 131-148, jul./dez. 2017. https://online.unisc.br/seer/index.php/cepe/index 


\section{CONSULTORIA INTERNA EM GESTÃO DE PESSOAS}

Em meados dos anos 1950, as referências no campo da consultoria emergiram especificamente na área médica e da saúde mental, e ao longo do tempo tal campo migrou dos consultórios e hospitais para a área organizacional (KURPIUS; ROBINSON, 1978). Ao ingressar no âmbito empresarial, a consultoria tem prosperado de forma crescente desde os anos 1980 motivada pela implementação de ferramentas gerenciais inspiradas nas práticas de gestão japonesas, sendo executada sob o enfoque interno ou externo (DONADONE, 2003). Neste estudo, será abordada a categoria interna da consultoria, exclusivamente o modelo de consultoria interna em gestão de pessoas.

A consultoria interna teve origem na Europa e nos Estados Unidos na década de 1950, contudo apenas se consolidou na década de 1990, em decorrência da demanda por mudanças estruturais, culturais e práticas para a competitividade organizacional (JOHRI; COOPER; PROKOPENKO, 1998). Tal movimento foi impulsionado pela busca de profissionais de recursos humanos habilitados para trabalhar com aspectos mais amplos da gestão, capazes de auxiliar as lideranças na resolução de problemas de diversas naturezas, como a diferenciação de salários, estratégias para desenvolvimento de pessoas, dificuldades com a equipe de trabalho e condução de processos de mudança (ALBERTON; MANCIA; BORBA, 2009).

No Brasil, a consultoria interna iniciou a partir da década de 1960 com a expansão do parque empresarial, a necessidade de atualização das técnicas de gestão e a melhoria contínua dos processos organizacionais. Entretanto, a efetiva utilização dessa forma de atuar em todo território foi decorrente das transformações do período pós-globalização da década de 1990, quando as empresas passaram a buscar novas formas de agregar valor aos negócios, aproximando-se de seus empregados e estimulando-os a conhecer a cultura organizacional e a participar da construção da estratégia (LEITE et al., 2009; MANCIA, 2010; OLIVEIRA, 2014).

Desse modo, a consultoria interna tem assumido papel importante nas organizações como prática de apoio à gestão e à agilidade das ações empresariais (GIRARDI; LAPOLLI; TOSTA, 2009). Destarte, diversos autores relatam inúmeros impactos da mesma sobre as organizações, apontando os benefícios inegáveis de tal atividade, dentre eles destacam-se: redução de custos em atividades realizadas por consultores internos, respostas rápidas em problemas emergenciais, responsabilidade pessoal sobre o monitoramento e implementação das tarefas, e preparação dos profissionais para posições de liderança (KELLEY, 1979; HANSEN et al., 1990; KENTON; MOODY; TAYLOR, 2003; ORLICKAS, 2013).

Enquanto componente da gestão de pessoas, a consultoria se ampliou na medida em que a área de Recursos Humanos passou de técnico-burocrática para humana e desenvolvimentista, conforme a evolução dos modelos da área descrita no Quadro 1. Por conseguinte, tal necessidade de mudança nos procedimentos e sistemas organizacionais possibilitou a atuação efetiva da área nos processos de Recrutamento e Seleção, Treinamento e Desenvolvimento, Cargos e Salários, entre outros (GIRARDI; LAPOLLI; TOSTA, 2009; LEITE et al., 2009).

Estudos do CEPE [ISSN 1982-6729]. Santa Cruz do Sul, n. 46, p. 131-148, jul./dez. 2017. https://online.unisc.br/seer/index.php/cepe/index 
Quadro 1 - Modelos de gestão de RH até a consultoria interna

\begin{tabular}{|c|c|c|c|}
\hline Modelo & $\begin{array}{l}\text { Administração de } \\
\text { Pessoal }\end{array}$ & $\begin{array}{l}\text { Administração de } \\
\text { Recursos Humanos }\end{array}$ & $\begin{array}{l}\text { Consultoria Interna em } \\
\text { Recursos Humanos }\end{array}$ \\
\hline $\begin{array}{l}\text { CONCEPÇÃO } \\
\text { SOBRE AS } \\
\text { PESSOAS }\end{array}$ & $\begin{array}{l}\text { Policiamento } \\
\text { Mandatário }\end{array}$ & $\begin{array}{l}\text { Valorização das } \\
\text { experiências }\end{array}$ & $\begin{array}{l}\text { Valorização das } \\
\text { competências e recurso } \\
\text { estratégico }\end{array}$ \\
\hline AÇÃO DE RH & $\begin{array}{l}\text { Controle jurídico, } \\
\text { administrativo e } \\
\text { legal }\end{array}$ & $\begin{array}{l}\text { Atuação mediante } \\
\text { especialidades }\end{array}$ & $\begin{array}{l}\text { Orientação para a } \\
\text { obtenção dos objetivos } \\
\text { estratégicos da empresa }\end{array}$ \\
\hline POLÍTICAS DE RH & Inexistentes & $\begin{array}{l}\text { Implícitas, algumas } \\
\text { vezes formalizadas }\end{array}$ & $\begin{array}{l}\text { Explícitas, normalmente } \\
\text { formalizadas e em } \\
\text { relação com os objetivos } \\
\text { estratégicos }\end{array}$ \\
\hline SISTEMAS & $\begin{array}{l}\text { Relacionados com } \\
\text { exigências legais e } \\
\text { ao pagamento de } \\
\text { salários }\end{array}$ & $\begin{array}{l}\text { Baseados na } \\
\text { utilização de várias } \\
\text { técnicas de } \\
\text { administração de RH }\end{array}$ & $\begin{array}{l}\text { Sofisticados, articulados } \\
\text { com a realização dos } \\
\text { objetivos estratégicos da } \\
\text { empresa }\end{array}$ \\
\hline STATUS & $\begin{array}{l}\text { Subordina a uma } \\
\text { gerência média }\end{array}$ & $\begin{array}{l}\text { Subordinado a uma } \\
\text { média ou alta gerência }\end{array}$ & $\begin{array}{l}\text { Subordinado ao principal } \\
\text { executivo ou parte } \\
\text { integrante de grupo } \\
\text { dirigente }\end{array}$ \\
\hline
\end{tabular}

Fonte: Orlickas (2013)

Milkovich e Boudreau (2010) destacam que diversas organizações atuam com um modelo de $\mathrm{RH}$ de alta flexibilidade, com líderes experientes que detém a ação sobre o negócio, acompanhados por representantes de $\mathrm{RH}$, os quais atuam como consultores internos, criando políticas adequadas as necessidades de cada unidade e transformando a organização em uma rede de alianças. Em tal modelo de descentralização da gestão, a responsabilidade por gerir pessoas não se restringe a uma única área e é compartilhada com os demais líderes, de modo que todos os gestores de áreas são também gestores de pessoas (LEITE et al., 2009; MANCIA, 2010; ORLICKAS, 2013).

Dentre as definições de consultoria interna em gestão de pessoas constata-se que tal processo é determinante para apoiar as ações dos líderes e auxiliá-los na solução dos problemas organizacionais (LEITE et at., 2009; CAPARAJÓ; LIRA, 2010; ORLICKAS, 2013). Contudo, Orlickas (2013) ressalta que o consultor interno de gestão de pessoas deve ser um agente facilitador que efetua levantamentos e diagnósticos do ambiente, estabelecendo um elo entre o cliente interno e o RH corporativo. Já Leite et. al. (2009) salientam que a mudança organizacional pode ser gerada pela própria consultoria interna em gestão de pessoas, através da realização de uma intervenção planejada com ênfase em toda a coletividade.

Estudos do CEPE [ISSN 1982-6729]. Santa Cruz do Sul, n. 46, p. 131-148, jul./dez. 2017. https://online.unisc.br/seer/index.php/cepe/index 
Para implantação de um processo de consultoria interna, Orlickas (2013) apresenta nove passos que a área de $\mathrm{RH}$ deve seguir, sendo eles:

a) Execução do benchmark: processo positivo e ativo para alterar os procedimentos da organização mediante a identificação das melhores práticas do mercado, porém as práticas a serem implantadas devem ser adaptadas as necessidades da empresa;

b) Conscientização de todos: os empregados, em geral, devem receber todas as informações referentes à necessidade, ao objetivo e às consequências do processo de implantação da consultoria interna, de modo que as outras fases aconteçam naturalmente;

c) Desburocratização e racionalização: eliminação de processos dificultadores da área de rh por meio da terceirização de atividades-meio e o investimento em sofwares;

d) Políticas de rh bem definidas: definição de políticas precisas, a fim de evitar futuras interferências e administrar apenas as exceções ao longo do processo;

e) Aplicação de job rotation (rodízio de funções): realizar a rotatividade dos consultores internos pelos diversos setores da empresa para enriquecer a atuação dos mesmos;

f) Sustentação administrativa e funcional: o consultor durante suas atividades precisa do suporte aos sistemas informatizados e apoio logístico de analistas;

g) Capacitação de cada profissional de rh: treinamento de todos os profissionais para que se obtenham um perfil generalista na área;

h) Definição do papel do consultor interno: a fim de evitar distorções no futuro, o papel do consultor interno deve ser estabelecido para conhecimento dos lideres e da própria área de rh;

i) Revisões e avaliações: realização de constantes revisões e realizações do processo para corrigi-lo e aperfeiçoá-lo diante a realidade da empresa.

Ao implantar tal processo, Silva (2013) aponta exclusivamente a necessidade de distinguir as duas funções essenciais do mesmo: o consultor interno (profissional da área de $\mathrm{RH}$ ), e os gestores de pessoas (líderes de diversas áreas). O consultor interno deve participar do planejamento estratégico da organização, elaborar políticas de gestão de pessoas, prestar assessoria e suporte aos clientes internos e propor ações de gestão de pessoas. Já, o gestor de pessoas tem a função de cuidar das pessoas de sua equipe, motivá-las, avaliá-las e tomar decisões a respeito delas, levantar necessidades de treinamento e comunicar as estratégias a equipe, transformando-as em ações (LEITE et al., 2009; ORLICKAS, 2013; SILVA, 2013).

Para o sucesso da consultoria interna em gestão de pessoas, além dos consultores internos e gestores de pessoas atuarem lado a lado, em prol do crescimento da organização e das pessoas, é fundamental o alinhamento de interesses na busca do fortalecimento do processo. A introdução de políticas, práticas e estratégias voltadas para as pessoas (plano de remuneração, carreira e retenção) precisam estar integradas com a estratégia da organização para que continuamente a empresa tenha profissionais capacitados e motivados para o trabalho (ORLICKAS, 2013). Por esse motivo, a próxima seção será destinada à discussão sobre os conceitos e características da gestão estratégica de pessoas.

Estudos do CEPE [ISSN 1982-6729]. Santa Cruz do Sul, n. 46, p. 131-148, jul./dez. 2017. https://online.unisc.br/seer/index.php/cepe/index 


\subsection{Pesquisas empíricas sobre consultoria interna em gestão de pessoas}

Ao se realizar um levantamento a nível nacional das pesquisas empíricas publicadas entre os anos de 2006 a 2016 nas bases de dados Scientific Periodicals Electronic Library (SPELL) e Scientific Electronic Library Online (SciELO), e nos eventos Encontro da Associação Nacional de PósGraduação em Administração (EnANPAD) e Encontro de Gestão de Pessoas e Relações de Trabalho (EnGPR), utilizando como título e palavras-chave "consultoria interna de recursos humanos" e "consultoria interna de gestão de pessoas", encontrou-se um pequeno número de trabalhos acerca do tema, sendo eles de Alberton, Mancia e Borba (2009), Caparajó e Lira (2009), Freitag e Girardi (2009), Girardi, Lapolli e Tosta (2009), Silva (2013) e, Lima e Fischer (2016).

Alberton, Mancia e Borba (2009) propuseram uma reflexão a respeito do papel do profissional que atua como Consultor Interno, contemplando os diversos aspectos que resultam com a adoção da estrutura de consultoria interna na área de Recursos Humanos. O estudo de caso foi realizado junto a dois grupos de profissionais da área de Recursos Humanos, totalizando 32 pessoas investigadas por meio de observação, durante dois cursos de Formação para Consultores Internos de Recursos Humanos realizados em 2007 e 2008. Os resultados apontaram a necessidade de um maior preparo dos profissionais de RH para atuarem nessa posição, pois não havia clareza, mesmo por parte dos sujeitos que já atuavam como Consultor Interno, do seu real papel dentro das empresas. Isso pode ocorrer tanto pelo fato das empresas não terem conhecimento a respeito do modelo de Consultoria Interna, quanto pelas dificuldades que o Consultor Interno tem para assumir as suas responsabilidades no processo. Além desses aspectos, também se identificou a importância do gestor da área de $\mathrm{RH}$ no processo de comunicação interna do modelo, em organizar a estrutura da área de RH para a atuação neste e, ainda, legitimar a ação dos Consultores Internos. Além disso, investigaram-se os limites de intervenção que o Consultor Interno se depara, sendo eles: falta de clareza do modelo, conflitos com o cliente em decorrência da tomada de decisão, baixa legitimação do seu papel e poder de influência. Por fim, revelou-se que o modelo de consultoria interna de $\mathrm{RH}$ ainda tem espaço para avançar, tanto nos estudos acadêmicos, quanto nos ambientes organizacionais, e que em tempos constantes de repensar a atuação da área de Recursos Humanos, entende-se que o modelo pode contribuir para um maior alinhamento entre atuação tática de $\mathrm{RH}$ e estratégia organizacional.

Sob um enfoque pertinente ao administrador hospitalar, Caparajó e Lira (2009) identificaram as vantagens de investimento na capacitação das médias gerências para que estas, assessoradas por um especialista em $\mathrm{RH}$, assumam a gestão das pessoas que compõe sua equipe. Foi realizada uma pesquisa de campo junto aos funcionários que compõe uma determinada equipe, sendo aplicados 292 questionários e realizadas 20 entrevistas, além de reuniões periódicas com a coordenação de um setor hospitalar. Os resultados mostraram que o nível de capacitação do gerente influencia muito na real necessidade do trabalho de um consultor, e que ainda não há uma consciência de que problemas com pessoas são da responsabilidade do gestor e não somente dos profissionais de RH. Observou-se ainda que a partir do momento em que os gerentes assumem a

Estudos do CEPE [ISSN 1982-6729]. Santa Cruz do Sul, n. 46, p. 131-148, jul./dez. 2017. https://online.unisc.br/seer/index.php/cepe/index 
função de gerenciar efetivamente sua equipe, há mais tempo para que o administrador hospitalar se dedique a assuntos estratégicos e mais abrangentes que permeiam o ambiente hospitalar, sendo o Consultor Interno a razão de ser do modelo, por facilitar a integração entre gestores e liderados, e por dar suporte para que esta relação envolva trocas justas. Por fim, o trabalho revela o quanto a consultoria em Gestão de Pessoas é atual, oportuna e pertinente, porém exercê-la requer alguns cuidados, tais como a dedicação e a determinação do profissional, visto haver grande necessidade de capacitação, estudo e experiência na área em que se atua.

O estudo realizado por Freitag e Girardi (2009) verificou de que forma a consultoria interna de recursos humanos poderia ser aplicada em uma empresa de pequeno porte, com uma estrutura enxuta de pessoal, com a finalidade de otimizar as atividades de gestão de pessoas naquele cenário. E, mais especificamente, a pesquisa objetivou contextualizar as Micro e Pequenas Empresas (MPEs) no país e em Santa Catarina, ao apresentar um estudo de campo da empresa Tipo A e relatar sua experiência da consultoria interna de $\mathrm{RH}$. Os resultados apontaram que é possível aplicar a Consultoria Interna de $\mathrm{RH}$ em uma empresa de pequeno porte da seguinte forma: tomando o responsável pelo setor como Consultor Interno, tendo como clientes internos os gerentes dos demais setores e delegando a eles atividades de atendimento a funcionários, assinatura de documentos, aviso de demissão e anúncio de promoção por exemplo. Contudo, a implantação dessa descentralização do setor de $\mathrm{RH}$ não foi formalizada, e como consequência, verificou-se a resistência da direção da empresa ao novo estilo de gestão de $\mathrm{RH}$. Nesse sentido, remondou-se à empresa a realização de um esforço de adesão da direção por meio da apresentação dos resultados positivos alcançados, e que fosse realizada a formalização da Consultoria Interna de RH em sua estrutura. Por fim, destacou-se a contribuição da experiência desenvolvida na empresa para o estudo da gestão de $\mathrm{RH}$, pois se tratou de uma inovação: a implantação do processo de Consultoria Interna de RH em uma empresa de pequeno porte.

Já Girardi, Lapolli e Tosta (2009) analisaram a contribuição da Consultoria Interna de Recursos Humanos para a Gestão do Conhecimento nas indústrias catarinenses de grande porte. Foram entrevistadas sete das maiores empresas catarinenses em número de funcionários. Os resultaram indicaram que a consultoria interna auxilia principalmente nas etapas de socialização (compartilhamento e criação do conhecimento tácito pela experiência direta) e externalização (criação e articulação do conhecimento tácito em conceitos explícitos) conforme a ótica da criação do conhecimento proposta pelos autores Nonaka e Takeuchi (1997). Além disso, se implementada na sua totalidade e dada autonomia ao consultor interno, permite uma maior interação nos níveis individual, grupal e organizacional. Assim, percebeu-se que as empresas que possuem maior grau de autonomia, bem como maior nível de implementação são aquelas que os processos são mais compartilhados, socializados e internalizados pelos funcionários. Dessa forma, afirmou-se que, nas empresas analisadas, o desenvolvimento dos processos de Consultoria Interna de Recursos Humanos catalisa os resultados da Gestão do Conhecimento nas mesmas.

Silva (2013) desenvolveu uma pesquisa para analisar as contribuições do modelo de consultoria interna de recursos humanos para o alinhamento entre as pessoas e a estratégia da empresa. Os dados foram coletados por meio de entrevistas estruturadas e semiestruturadas e

Estudos do CEPE [ISSN 1982-6729]. Santa Cruz do Sul, n. 46, p. 131-148, jul./dez. 2017. https://online.unisc.br/seer/index.php/cepe/index 
documentos de uma empresa de grande porte, localizada na Região Sul do Brasil. Os resultados demonstraram que o modelo de consultoria interna de recursos humanos, associado às políticas e práticas de gestão de pessoas, contribuiu para o alinhamento entre as pessoas e a estratégia da empresa, pois conferiu um olhar sistêmico sobre a organização, atribuiu à área de gestão de pessoas um papel de apoio à gestão e impulsionou o projeto empresarial. Além disso, a rapidez de comunicação e a proximidade entre líderes e equipes facilitaram o vínculo com as pessoas, estimulando-as a caminharem na direção dos resultados da empresa, fazendo-as entender que os objetivos da empresa representam seus objetivos também. Tal alinhamento se mostra evidente na própria nomenclatura da área de Recursos Humanos, anteriormente denominada de "desenvolvimento humano", passando na ocasião da implantação do modelo de consultoria, a se chamar "desenvolvimento organizacional", uma vez que permite conciliar os interesses de ambas as partes, compreendendo que as pessoas fazem parte do sistema organizacional e não podem ser tratadas separadamente.

Por fim, Lima e Fischer (2016) investigaram se as empresas que optaram por adotar em suas Áreas de Recursos Humanos (ARH) o modelo de consultoria interna inovam mais em suas práticas de gestão, do que as que possuem uma atuação tradicional. Foram utilizados dados secundários pertencentes a um universo constituído por 541 empresas nacionais e multinacionais de diferentes portes, e 139 mil profissionais participantes de uma pesquisa longitudinal entre os anos de 2007 a 2011, com foco na identificação dos índices de qualidade do ambiente de trabalho e das práticas de em recursos humanos. Os achados evidenciaram que as ARH que adotam a consultoria interna possuíam 64 práticas em 2007 e 128 em 2011, enquanto que as tradicionais saíram de 59 práticas em 2007 para 127 em 2011. Ademais, percebeu-se que 7\% das empresas que adotam o modelo de consultoria interna não possuem um aumento constante das práticas ao longo dos anos, já $14 \%$ das ARH que adotaram o modelo tradicional não obtiveram um aumento progressivo das práticas. Além disso, se verificou que a ARH com consultoria interna inovou pouco mais (128 práticas), em termos de aumento de práticas do que a tradicional (127 práticas), sendo esse resultado não considerado significativo estatisticamente. Assim, sugeriu-se uma agenda de pesquisa para o aprofundamento do tema, tais como: a verificação das práticas de gestão que foram excluídas, das razões, motivos e dos impactos de sua ausência; e as diferenças dos resultados de gestão de clima e posicionamento no mercado das empresas que possuem a consultoria interna e das que não possuem.

\section{GESTÃO ESTRATÉGICA DE PESSOAS}

A área de recursos humanos tradicionalmente voltada às atividades administrativas, anteriormente intitulada departamento de pessoal, passou por significativas transformações nas organizações durante as últimas décadas, até alcançar a atual condição estratégica, denominada gestão estratégica de pessoas. Tal abordagem estratégica surgiu no início da década de 1980, alicerçada no alinhamento entre a gestão de pessoas e as estratégias organizacionais (VENTURA; LEITE, 2014).

Estudos do CEPE [ISSN 1982-6729]. Santa Cruz do Sul, n. 46, p. 131-148, jul./dez. 2017. https://online.unisc.br/seer/index.php/cepe/index 
No período de transição do $\mathrm{RH}$ tradicional para a gestão estratégica de pessoas, como mostra o Quadro 2, contata-se uma grande mudança na visão das organizações sobre as pessoas, seu desenvolvimento e talentos. Logo, as pessoas passaram a representar uma potencial vantagem competitiva para as organizações, cabendo à área de gestão de pessoas atuar de forma estratégica para melhor gestão dessas vantagens (LENGNICK-HALL et. al., 2009). Entre as principais mudanças na área, destacam-se a ênfase nos resultados ao longo prazo com desenvolvimento contínuo, melhor aproveitamento dos talentos e obtenção de vantagens competitivas por meio de pessoas comprometidas, saudáveis e motivadas (FLEURY, 2002; MASCARENHAS, 2011).

\section{Quadro 2 - Mudanças na perspectiva tradicional e estratégica na gestão de pessoas}

\begin{tabular}{|c|c|c|}
\hline Mudanças & RH Tradicional & $\begin{array}{l}\text { Gestão Estratégica de } \\
\text { pessoas }\end{array}$ \\
\hline FUNÇÕES & $\begin{array}{l}\text { Funções tradicionais: } \\
\text { captação, remuneração, } \\
\text { treinamento e avaliação de } \\
\text { desempenho }\end{array}$ & $\begin{array}{l}\text { Alinhamento e participação na } \\
\text { estratégia das empresas, papel de } \\
\text { parceiro nas mudanças, com } \\
\text { funções de consultoria interna a } \\
\text { outros setores e visão holística dos } \\
\text { processos da organização }\end{array}$ \\
\hline $\begin{array}{l}\text { POSTURA EM RELAÇÃO } \\
\text { ÀS PESSOAS }\end{array}$ & $\begin{array}{l}\text { Preocupação com o resultado } \\
\text { imediato dos colaboradores; } \\
\text { eficiência produtiva e } \\
\text { mecanicista }\end{array}$ & $\begin{array}{l}\text { Preocupação com o } \\
\text { desenvolvimento contínuo das } \\
\text { pessoas nas organizações, focando } \\
\text { na obtenção de vantagens } \\
\text { competitivas através do } \\
\text { comprometimento das pessoas e da } \\
\text { qualidade de vida no trabalho e } \\
\text { melhor aproveitamento dos talentos }\end{array}$ \\
\hline $\begin{array}{l}\text { CRITÉRIO DE QUALIDADE } \\
\text { PARA A ATUAÇÃO DA } \\
\text { ÁREA DE GESTÃO DE } \\
\text { PESSOAS }\end{array}$ & $\begin{array}{l}\text { Eficiência nos processos } \\
\text { internos cotidianos dos } \\
\text { funcionários }\end{array}$ & $\begin{array}{l}\text { Eficácia na realização das } \\
\text { atividades rotineiras em busca de } \\
\text { consistência interna da área } \\
\text { conciliada, no entanto, com o } \\
\text { alinhamento para com as atividades } \\
\text { e necessidades dos outros } \\
\text { departamentos }\end{array}$ \\
\hline
\end{tabular}

Fonte: Elaborado a partir de Fleury (2002) e Mascarenhas (2011).

Destarte, a postura estratégica da área de gestão de pessoas, abrangendo políticas, práticas, estratégias e filosofias vinculadas aos objetivos e metas empresariais foi motivada pelas mudanças nos modelos organizacionais, responsáveis por alterar o gerenciamento de recursos humanos, em virtude do cenário altamente competitivo. Nessa nova filosofia, os indivíduos são vistos como ativos

Estudos do CEPE [ISSN 1982-6729]. Santa Cruz do Sul, n. 46, p. 131-148, jul./dez. 2017. https://online.unisc.br/seer/index.php/cepe/index 
(assets) organizacionais e a relação de trabalho como um jogo de soma positiva - ganha-ganha, ou seja, as pessoas são consideras relevantes na construção das competências organizacionais e na obtenção de resultados por serem produtoras de conhecimento e inovação (KAUFMAN, 2008; MARTÍN-ALCÁZAR; ROMERO-FERNÁNDEZ; SÁNCHEZ-GARDEY, 2008; BOHLANDER; SNELL, 2010).

Diversos autores nacionais (FLEURY, 2002; DUTRA, 2008; LEITE; ALBUQUERQUE, 2009; MASCARENHAS, 2011; WOOD JR; TONELLI; COOKE, 2011; MASCARENHAS; BARBOSA, 2013; VENTURA; LEITE, 2014; PRIMO; OLIVA; KUBO, 2014) e estrangeiros (ULRICH, 1998; KAUFMAN, 2008; MARTÍN-ALCÁZAR; ROMERO-FERNÁNDEZ; SÁNCHEZ-GARDEY, 2008; BOHLANDER; SNELL, 2010) debruçaram sobre as transformações ocorridas na área de gestão de pessoas, definindo e esclarecendo tal abordagem estratégica emergente na mesma.

Dentre as perspectivas de tais autores, destacam-se as percepções de Dutra (2008), Leite e Albuquerque (2009) e Bohlander e Snell (2010) ao considerar que a gestão estratégica de pessoas lança sua atenção à conquista e à retenção de talentos que se comprometam com os ideais da organização, e principalmente os prepara em função dos objetivos organizacionais vinculados de forma integrada aos objetivos individuais. Desse modo, a gestão estratégica de pessoas pode ser entendida como um conjunto de ações que visa o desempenho (performance) individual e organizacional.

Para elevar o desempenho organizacional é preciso compreender as complementaridades entre as práticas de gestão de pessoas e as diretrizes estratégicas da organização. Nesse sentido, Wood (1999) identificou quatro formas de alinhamento estratégico que a gestão estratégica de pessoas deve enfatizar: o alinhamento interno ou horizontal (integração entre as próprias práticas de gestão estratégica de pessoas); o alinhamento organizacional (ajuste entre as práticas de gestão estratégica de pessoas e os aspectos internos da organização); o alinhamento estratégico (articulação e reciprocidade entre as práticas de gestão estratégica de pessoas e a estratégia de negócio); e o alinhamento ambiental interno ou vertical (concordância entre as práticas da gestão estratégicas de pessoas e as contingências externas a organização).

Wei (2006) considera esses quatro tipos de alinhamento em apenas dois alinhamentos básicos independentes, contudo interrelacionados, são eles: o alinhamento interno e externo. Segundo o autor, ambos os alinhamentos sofrem influência de pelo menos três aspectos organizacionais: a competência dos gestores da própria área de gestão de pessoas, as competências e o suporte concedido pelos demais gestores da organização, e as características dos próprios indivíduos na organização, tais como suas habilidades, motivações e níveis de compromisso. Desse modo, as práticas de gestão estratégica de pessoas, em todos os níveis hierárquicos, devem estar alinhadas e compatíveis com a estratégia definida pela organização, para que possam efetivamente contribuir para o alcance dos objetivos organizacionais (SILVEIRA, 2014).

A fim de direcionar o planejamento, as políticas e práticas de $\mathrm{RH}$, as estratégias de gestão de pessoas podem ser caracterizadas como modelo soft (ênfase no desenvolvimento, individualização e motivação) ou modelo hard (ênfase aos objetivos coletivos, na harmonia e no uso de termos impessoais como força de trabalho e recursos humanos). O modelo soft é mais adequado para

Estudos do CEPE [ISSN 1982-6729]. Santa Cruz do Sul, n. 46, p. 131-148, jul./dez. 2017. https://online.unisc.br/seer/index.php/cepe/index 
organizações inseridas em cenários instáveis, que exigem estruturas mais flexíveis e maior envolvimento dos empregados. Já o modelo hard é mais apropriado para cenários estáveis, que enfatizam a produtividade e comportamentos repetitivos (TRUSS et al., 1997; MASCARENHAS, 2011).

Legge (2005) apresenta uma perspectiva crítica em relação aos modelos soft e hard. Para o autor, existia uma tendência no processo de alinhamento entre a gestão de pessoas e a estratégia organizacional em escolher entre uma estratégia de gestão de pessoas hard ou soft. Contudo, atualmente identifica-se que não é uma questão de escolher "um dos dois" ou "ou uma" estratégia, mas sim de "ambos" ou "e", incorporando mais de uma estratégia à gestão de pessoas.

Sob outro ângulo, Ulrich (1998) ressalta que além de dispor de estratégias, práticas e políticas alinhadas, a área de gestão de pessoas também deve fazer parte da estratégia da organização, tornando-se parceira nos negócios, de modo a auxiliar e impulsionar a organização a se tornar cada vez mais competitiva. Para isso, a área deve mostrar o seu valor à organização, assumindo gradualmente os seguintes múltiplos papéis: administração de estratégias de $\mathrm{RH}$ participação ativa no processo de definição da estratégia empresarial e ajustes nas estratégias de $\mathrm{RH}$; administração da infraestrutura da empresa - busca de melhoria contínua dos processos e atividades, visando aumentar a eficiência administrativa; administração da contribuição dos funcionários - reconhecimento, envolvimento e atendimento as demandas, preocupações, anseios e necessidades dos funcionários; e administração da transformação e da mudança - catalisação das mudanças e condução de processos cruciais de mudança no interior das empresas (ULRICH, 1998).

Dutra (2008) e Tanure, Evans e Cançado (2010) apontam que para promover a integração das práticas e políticas de gestão de pessoas à estratégia organizacional, tais práticas devem ser categorizadas de maneira que todas as funções da área de $\mathrm{RH}$ sejam efetivamente realizadas. Ademais, as organizações precisam favorecer e estimular a excelência no relacionamento interpessoal, o envolvimento dos empregados e a comunicação eficaz para atingir os objetivos organizacionais (BOHLANDER; SNELL, 2010).

A formulação de políticas e práticas de gestão de pessoas deve partir da estratégia organizacional, porém, também deve incluir outros aspectos que afetam diretamente a gestão de pessoas (BREWSTER, 2006). Embora cada empresa tenha sua própria estratégia, ela sofre diversas pressões externas, pela incerteza do mercado e pela evolução tecnológica. Por isso, é indispensável investigar e monitorar as forças ambientais (tecnológicas, socioeconômicas, culturais, políticas, e legais) e as forças internas (capacidades, cultura, e recursos), a fim de estabelecer um adequado planejamento estratégico para a gestão de pessoas (BREWSTER, 2006; LACOMBE; CHU, 2008).

Portanto, o foco da gestão estratégica de pessoas concentra-se no elo entre o desempenho humano e os negócios da organização, e as políticas de gestão de pessoas voltadas para a promoção da valorização e realização pessoal e profissional, são: política de recrutamento e seleção; política de envolvimento; política de treinamento, desenvolvimento e educação; política de condições do trabalho; política de avaliação de desempenho e competências; e política de recompensas (MASCARENHAS, 2011; DEMO; MARTINS; ROURE, 2013).

Estudos do CEPE [ISSN 1982-6729]. Santa Cruz do Sul, n. 46, p. 131-148, jul./dez. 2017. https://online.unisc.br/seer/index.php/cepe/index 
A fim de favorecer a atuação estratégica da área de gestão de pessoas, o modelo de consultoria interna apresenta diversas contribuições para abordagem estratégica da gestão de pessoas. Por isso, a próxima seção será reservada à compreensão de tal contribuição.

\section{A CONTRIBUIÇÃO DA CONSULTORIA INTERNA EM GESTÃO DE PESSOAS PARA A ATUAÇÃO DA GESTÃO ESTRATÉGICA DE PESSOAS}

$\mathrm{Na}$ busca por gerenciar pessoas de forma mais estratégica, o modelo de consultoria interna em gestão de pessoas representa um apoio à gestão da empresa, em que a área de gestão de pessoas é estruturada e organizada de maneira diferenciada da tradicional, conferindo maior interação, envolvimento e comunicação entre as pessoas (LEITE et al., 2009).

Em tal modelo, a área de gestão de pessoas detém maior proximidade com as demais áreas e está envolvida com os detalhes do negócio, participando ativamente da construção da estratégia e estimulando as pessoas a conhecerem a cultura organizacional, caminhando, desse modo, na direção dos resultados organizacionais (SILVA, 2013). Além disso, Silva (2013) ressalta que o modelo de consultoria interna representa um canal de comunicação, ligando a empresa aos empregados, e tal facilidade de comunicação confere que a estratégia empresarial seja construída e transmitida às pessoas pelos gestores que atuam diretamente nas equipes.

Leite et al. (2009) destacam que o consultor interno da área de gestão de pessoas deve atuar como um elo entre o cliente interno, o RH corporativo e as estratégias organizacionais, sendo suas atribuições fundamentais para auxiliar as lideranças na condução de equipes altamente engajadas e comprometidas com as metas da organização. Ademais, seu papel é assessorar estrategicamente os clientes internos, orientando os gestores na solução de problemas, participando de processos específicos, e acompanhando o desempenho individual e organizacional, de modo a garantir uma comunicação eficaz em busca do alinhamento entre as pessoas e a estratégia da empresa (LEITE et al., 2009; ORLICKAS, 2013).

Ao basear-se nos múltiplos papéis para a gestão estratégica de $\mathrm{RH}$ desenvolvidos por Ulrich (1998), as funções do consultor interno em gestão de pessoas se enquadram precisamente em cada papel, estabelecido segundo a meta a ser cumprida pela área, conforme mostra o Quadro 3.

\section{Quadro 3 - Os múltiplos papéis do RH estratégico e as funções do consultor interno}

\begin{tabular}{|l|l|l|l|}
\hline \multicolumn{1}{|c|}{ Papéis } & \multicolumn{1}{|c|}{ Resultado } & \multicolumn{1}{c|}{\begin{tabular}{c}
\multicolumn{1}{c|}{ Funções do } \\
Consultor Interno
\end{tabular}} \\
\hline $\begin{array}{l}\text { Administração de } \\
\text { Estratégias de } \mathrm{RH}\end{array}$ & $\begin{array}{l}\text { Execução da } \\
\text { Estratégia }\end{array}$ & Parceiro Estratégico & $\begin{array}{l}\text { Participação ativa no } \\
\text { desdobramento das } \\
\text { estratégias e práticas } \\
\text { empresariais e de RH }\end{array}$ \\
\hline
\end{tabular}

Estudos do CEPE [ISSN 1982-6729]. Santa Cruz do Sul, n. 46, p. 131-148, jul./dez. 2017. https://online.unisc.br/seer/index.php/cepe/index 


\begin{tabular}{|l|l|l|l|}
\hline $\begin{array}{l}\text { Administração da } \\
\text { Infraestrutura da } \\
\text { Empresa }\end{array}$ & $\begin{array}{l}\text { Construção de uma } \\
\text { infraestrutura eficiente }\end{array}$ & $\begin{array}{l}\text { Especialista } \\
\text { Administrativo }\end{array}$ & $\begin{array}{l}\text { Eficiência no } \\
\text { atendimento as } \\
\text { demandas do cliente } \\
\text { interno }\end{array}$ \\
\hline $\begin{array}{l}\text { Administração da } \\
\text { Contribuição dos } \\
\text { Funcionários }\end{array}$ & $\begin{array}{l}\text { Aumento do } \\
\text { envolvimento e } \\
\text { capacidade dos } \\
\text { funcionários }\end{array}$ & $\begin{array}{l}\text { Defensor dos } \\
\text { Funcionários }\end{array}$ & $\begin{array}{l}\text { Envolvimento com a } \\
\text { realidade da equipe e } \\
\text { atendimento exclusivo a } \\
\text { um setor }\end{array}$ \\
\hline $\begin{array}{l}\text { Administração da } \\
\text { Transformação e da } \\
\text { Mudança }\end{array}$ & $\begin{array}{l}\text { Criação de uma } \\
\text { organização renovada }\end{array}$ & Agente de Mudança & $\begin{array}{l}\text { Dinamização e auxílio } \\
\text { em processos de } \\
\text { mudança, minimizando } \\
\text { as futuras resistências }\end{array}$ \\
\hline
\end{tabular}

Fonte: Adaptado de Ulrich (1998).

O Quadro 3 indica a contribuição do consultor interno em gestão de pessoas para o resultado a ser alcançado na definição da atuação da gestão estratégica de $\mathrm{RH}$, sendo estabelecida segundo as seguintes metáforas criadas por Ulrich (1998):

a) Parceiro estratégico: o consultor interno participa do desdobramento das estratégias organizacionais assessorando os líderes sobre a necessidade de adequações das competências individuais as estratégias organizacionais, e ao mesmo tempo, sua própria atividade endossa a aplicação da atuação estratégica da área de gestão de pessoas;

b) Especialista administrativo: o consultor interno promove a melhoria contínua dos processos e atividades rotineiras da área de rh, atendendo prontamente as demandas do cliente interno por meio da simplificação dos processos, redução de tempo e custos, e eliminação de desperdícios;

c) Defensor dos funcionários: o consultor interno envolve-se com a realidade e o trabalho cotidiano da área que auxilia, dispondo de mecanismos capazes de ouvir, responder e encontrar maneiras de atender exclusivamente as demandas dos indivíduos da sua unidade de negócio, que passam ter mais confiança na área de gestão de pessoas;

d) Agente de mudança: o consultor interno facilita os processos de mudança, de modo a intervir junto as pessoas, assessorando e criando um vínculo de confiança, estabelecendo relações saudáveis e ao mesmo tempo, aumentando a possibilidade de superar objeções e reduzir a resistência proporcionada.

Os consultores internos devem estar estruturados estrategicamente por unidades de negócios, de tal maneira a auxiliar os líderes na promoção de uma comunicação clara e transparente, de forma a preservar pessoas qualificadas, comprometidas e engajadas na estratégia do negócio. As atividades dos mesmos proporcionam as seguintes vantagens para a área de gestão de pessoas, e consequentemente para as organizações: redução de custos pelo encolhimento da estrutura organizacional da área, rapidez na resolução de problemas, facilidade de comunicação, que favorece a compreensão da cultura organização e da estratégia organizacional por parte das pessoas em

Estudos do CEPE [ISSN 1982-6729]. Santa Cruz do Sul, n. 46, p. 131-148, jul./dez. 2017. https://online.unisc.br/seer/index.php/cepe/index 
todas as unidades de negócios, e proximidade entre líderes e liderados, gerando uma relação de confiança entre ambos (SILVA, 2013).

Diante disso, a associação do modelo de consultoria interna, as práticas e políticas de $\mathrm{RH}$ contribuem para o alinhamento entre as pessoas e a estratégia da organização, e, assim, para a atuação estratégica da área de gestão de pessoas. Contata-se que tal modelo atribui um olhar sistêmico sobre a organização, conferindo à área de gestão de pessoas um papel de apoio à gestão, além de assegurar a rapidez da comunicação e a proximidade entre líderes e equipes, estimulandoos a deslocarem na direção dos resultados da empresa, fazendo-os entender que os objetivos organizacionais também representam seus objetivos (SILVA, 2013).

\section{CONSIDERAÇÕES FINAIS}

Este estudo teve como objetivo compreender como a consultoria interna em gestão de pessoas contribui para a atuação da gestão estratégica de pessoas. Para atingi-lo, investigou-se na literatura sobre o assunto e nas pesquisas empíricas, o que os principais autores desse campo destacam sobre tal contribuição. Constatou-se que a consultoria interna em gestão de pessoas é caracterizada como um dos modelos de gestão da área, que objetiva dar respostas às exigências do complexo cenário econômico e às mudanças na organização do trabalho, conforme ressalta Mancia (2010).

Desse modo, ela permite a destituição do modelo mecanicista e reducionista administrado pelas organizações tradicionais, favorecendo o trabalho cooperativo, provido de responsabilidade e confiança a curto, médio e longo prazos. Além disso, Silva (2013) aponta que a associação do modelo de consultoria interna às práticas e políticas de $\mathrm{RH}$, contribui para o alinhamento entre as pessoas e a estratégia da organização, e, assim, para a atuação estratégica da área de gestão de pessoas.

Tal modelo de consultoria interna atribui um olhar sistêmico sobre a organização, conferindo à área de gestão de pessoas um papel de apoio à gestão. Ademais, é capaz de assegurar a rapidez e a transparência da comunicação, acompanhar o desempenho individual e organizacional, e aproximar líderes e equipes, estimulando-os a caminharem na direção dos resultados da empresa, fazendo-os compreender que os objetivos organizacionais também representam seus objetivos (LEITE et al., 2009; SILVA, 2013).

Além disso, destaca-se nesse modelo, a função do consultor interno que atua como um elo entre o cliente interno, o RH corporativo e as estratégias organizacionais, auxiliando as lideranças na condução de equipes altamente engajadas e comprometidas com as metas da organização (LEITE et al., 2009). Ao basear-se nos múltiplos papéis para a gestão estratégica de RH desenvolvidos por Ulrich (1998), as funções do consultor interno em gestão de pessoas se enquadram precisamente em cada papel - parceiro estratégico, especialista administrativo, defensor dos funcionários e agente de mudança, ratificando a contribuição do modelo de interna em gestão de pessoas para a atuação estratégica da área.

Estudos do CEPE [ISSN 1982-6729]. Santa Cruz do Sul, n. 46, p. 131-148, jul./dez. 2017. https://online.unisc.br/seer/index.php/cepe/index 
Em relação às pesquisas empíricas em âmbito nacional, contata-se a ausência de um número expressivo de trabalhos publicados sobre o tema nos últimos anos, o que revela a necessidade de aprofundamento e compreensão da aplicação desse modelo de gestão na realidade das organizações brasileiras. É notória a relação positiva que existe entre o modelo de consultoria interna de gestão de pessoas e a atuação estratégica da área em empresas de pequeno, médio ou grande porte, conforme ratificaram os seis estudos identificados (ALBERTON; MANCIA; BORBA, 2009; CAPARAJÓ; LIRA, 2009; FREITAG; GIRARDI, 2009; GIRARDI; LAPOLLI; TOSTA, 2009; SILVA, 2013; LIMA; FISCHER, 2016).

Entretanto, esses estudos revelam algumas evidências que podem estar diretamente relacionadas ao sucesso do modelo de consultoria interna: a) preparação do consultor para exercer a função consciente de suas atribuições e responsabilidades; b) preparação do gestor para liderar sua equipe e compreender o papel do consultor nesse processo; e, c) preparação da alta administração, e posteriormente de toda a organização a respeito das vantagens e atribuições do modelo de consultoria interna. Acredita-se que a aplicação destas três etapas anteriores a implantação do processo de consultoria interna pode assegurar a contribuição do modelo para a atuação estratégica das pessoas nos negócios.

Assim, fica evidente a contribuição da consultoria interna para a atuação da gestão estratégica de pessoas, uma vez que o modelo de consultoria interna incorporado às estratégias e práticas de gestão de pessoas possibilita o alinhamento entre as pessoas e a estratégia corporativa. Além de favorecer a comunicação entre líderes e equipes e estimular uma relação de confiança entre os indivíduos, a área de gestão de pessoas e a própria organização.

Portanto, uma das contribuições deste ensaio teórico é apresentar um compêndio teórico e empírico com base em concepções de diversos autores acerca da colaboração do modelo de consultoria interna para a atuação da gestão estratégica de pessoas nas organizações. Além disso, outra contribuição que este estudo revela é a reflexão sobre a demanda de um número maior de pesquisas realizadas em ambientes organizacionais com o propósito de aplicar e legitimar a teoria em relação ao tema. Para o desenvolvimento dessas novas pesquisas, sugere-se a investigação dos seguintes aspectos:

a) Implantação do modelo de consultoria interna segundo as diretrizes dos noves passos desenvolvidos por Orlickas (2013), sendo eles: execução de benchmark, conscientização de todos, desburocratização e racionalização, políticas de RH bem definidas, aplicação de job rotation, sustentação administrativa e funcional, capacitação de cada profissional de $\mathrm{RH}$, definição do papel do consultor, revisões e avaliações;

b) Comparação entre empresas que ainda não adotaram o modelo de consultoria interna de gestão de pessoas e empresas já adotaram, a fim de validar a divergência existente entre a Administração de Recursos Humanos e a Consultoria de Interna de RH conforme o modelo de gestão de RH proposto por Orlickas (Quadro 1 - capítulo 2), bem como evidenciar a contribuição dos modelos para uma gestão estratégica das pessoas;

c) Descrição das funções do consultor interno de gestão de pessoas para o alcance da gestão estratégica das pessoas, ratificando a existência e a efetividade das quatro metáforas

Estudos do CEPE [ISSN 1982-6729]. Santa Cruz do Sul, n. 46, p. 131-148, jul./dez. 2017. https://online.unisc.br/seer/index.php/cepe/index 
(parceiro estratégico, especialista administrativo, defensor dos funcionários, agente de mudança) criadas por Ulrich (1998).

\section{REFERÊNCIAS}

ALBERTON, D. M.; MANCIA, L. T.; BORBA, P. M. O papel do consultor interno de recursos humanos. In: XXXIII Encontro Nacional da Associação Nacional de Pós-Graduação e Pesquisas em Administração, 2009, São Paulo. Anais... São Paulo: ANPAD, 2009.

BOHLANDER, G.; SNELL, S. Administração de recursos humanos. São Paulo: Cengage Learning, 2010.

BREWSTER, C. Comparing HRM policies and practices across geographical borders. In: STAHL, G.; BJORKMAN, I. Handbook of Research in International Human Resource Management. Cheltenham, UK: Edward Elgar Publishing, 2006.

CARAPAJÓ, A. B. A.; LIRA, R. A. Consultoria interna em gestão de pessoas: uma estratégia viável para o administrador hospitalar. In: XXXIV Encontro Nacional da Associação Nacional de PósGraduação e Pesquisas em Administração, 2010, Rio de Janeiro. Anais... Rio de Janeiro: ANPAD, 2010.

DEMO, G.; MARTINS, P. R.; ROURE, P. Políticas de gestão de pessoas, comprometimento e satisfação no trabalho na Livraria Cultura. Revista Alcance - Eletrônica, v. 20 , n.2 - p. 237-254, abr./jun. 2013.

DONADONE, J. C. O mercado internacional de consultorias nas últimas décadas: crescimento, diversificação e formas de disputa. Caderno de Pesquisas em Administração, v. 10, n. 2, p. 1-15, jun. 2003.

DUTRA, J. S. Competências: conceitos e instrumentos para a gestão de pessoas na organização moderna. São Paulo: Atlas, 2008.

FLEURY, M. T. L. A gestão de competência e a estratégia organizacional, In: FLEURY, M. T.(Coord.). As pessoas na organização. São Paulo: Gente, 2002.

FREITAG, B. B.; GIRARDI, D. Consultoria Interna de RH em uma empresa de pequeno porte. In: XXXIII Encontro Nacional da Associação Nacional de Pós-Graduação e Pesquisas em Administração, 2009, São Paulo. Anais... São Paulo: ANPAD, 2009.

GIRARDI, D. M.; LAPOLLI, M.; TOSTA, K. C. B. T. A consultoria interna de recursos humanos como prática catalisadora da gestão do conhecimento organizacional. Revista de Ciências da Administração, v. 11, n. 25, p. 151-176, 2009.

HANSEN, J. et al. Consultoration: concepts and practices. New Jersey: Prentice Hall, 1990.

JOHRI, H. P.; COOPER, J. C.; PROKOPENKO, J. Managing internal consulting organizations: a new paradigm. Advanced Management Journal, v. 63, n. 4, p. 4-10, Outono 1998.

KAUFMAN, B. E. Managing the human factor: the early years of human resource management in American industry. Ithaca - NY: Cornell University Press, 2008.

KELLEY, R. E. Should you have an internal consultant? Harvard Business Review, v. 57, n. 6, p. 110120, nov./dez. 1979.

KENTON, B.; MOODY, D.; TAYLOR, B. The role of the internal consultant. Roffey Park Institute. 2003.

Estudos do CEPE [ISSN 1982-6729]. Santa Cruz do Sul, n. 46, p. 131-148, jul./dez. 2017. https://online.unisc.br/seer/index.php/cepe/index 
KURPIUS, D.; ROBINSON, S. An overview of consultation. Personal and Guidance Journal, p. 321323, Feb. 1978.

LACOMBE, B.; CHU, R. A. Políticas e práticas de gestão de pessoas: as abordagens estratégica e institucional. Revista de Administração Eletrônica, v. 48, n. 1. jan./mar. 2008.

LEGGE, K. Human resource management: rhetorics and realities. London: Macmillan, 1995.

LEITE, L. A. M. C. et al. Consultoria em gestão de pessoas. 2. ed. Rio de Janeiro: FGV, 2009.

LEITE, N. P.; ALBUQUERQUE, L. G. Gestão estratégica de pessoas: conceito, evolução e visão. In: ALBUQUERQUE, L. G.; LEITE, N. P. (Org.). Gestão de pessoas: perspectivas estratégicas. São Paulo: Atlas, 2009.

LENGNICK-HALL, M. L. et al. Strategic human resource management: the evolution of the field. Human Resource Management Review, v. 19, n. 2, p. 64-85, 2009.

LIMA, L. C.; FISCHER, A. L. Estudo preliminar sobre a atuação da área de Recursos Humanos como Consultoria Interna e sua capacidade de inovação das práticas de gestão. Revista de Administração da UFSM, v. 9, n. 3, p. 391-407, 2016.

MANCIA, L. Os desafios do modelo de consultoria interna. In: BITENCOURT, C. C. Gestão contemporânea de pessoas: novas práticas, conceitos tradicionais. 2. ed. Porto Alegre: Bookman, 2010.

MARTíN-ALCÁZAR, F., ROMERO-FERNÁNDEZ, P. M., SÁNCHEZ-GARDEY, G. Human Resource Management as a field of research. British Journal of Management, v. 19, n. 2, p. 103-119, 2008.

MASCARENHAS, A. O. Gestão estratégica de pessoas: evolução teoria e crítica. São Paulo: Cangage Learning, 2011.

MASCARENHAS, A. O.; BARBOSA, A. C. Q. Produção científica brasileira em gestão de pessoas no período 2000-2010. Revista de Administração de Organizações - RAE, v. 53, n. 1, p. 35-45. São Paulo: FGV, jan/ fev. 2013.

MILKOVICH, G. T.; BOUDREAU, J. W. Administração de recursos humanos. São Paulo: Atlas, 2010.

OLIVEIRA, D. P. R. Manual de consultoria empresarial: conceitos, metodologia, práticas. 12. ed. São Paulo: Atlas, 2014.

ORLICKAS, E. Consultoria interna de recursos humanos: conceitos, benchmarking, cases, indicadores. 11. ed. São Paulo: Danielli Editores, 2013.

PRIMO, P. P.; OLIVA, E. C.; KUBO, E. K. M. Gestão estratégica de pessoas para pesquisadores em Administração nas universidades privadas. REAd. Revista Eletrônica de Administração, v. 20, n. 2, p. 371-396, 2014.

SILVA, D. R. As contribuições do modelo de consultoria interna de recursos humanos para o alinhamento entre as pessoas e a estratégia da empresa. DESENVOLVE: Revista de Gestão do Unilasalle, v. 2, n. 2, p. 169-185, set. 2013.

SILVEIRA, V. N. S. Alinhamento estratégico e gestão estratégica de pessoas: análise conceitual e perspectivas teóricas. Revista Pretexto, v. 15, n. 4, p. 114-133, 2014.

SILVEIRA, V. N. S.; MAESTRO FILHO, A. D. Gestão estratégica de pessoas e desempenho organizacional: uma análise teórica. Revista Pretexto, v. 14, n. 1, p. 71-87, 2013.

TANURE, B.; EVANS, P.; CANÇADO, V. L. As quatro faces de RH: analisando a performance da gestão de Recursos Humanos em organizações no Brasil. Revista de Administração Contemporânea - RAC, v.14, n.4, p. 594-614, 2010.

Estudos do CEPE [ISSN 1982-6729]. Santa Cruz do Sul, n. 46, p. 131-148, jul./dez. 2017. https://online.unisc.br/seer/index.php/cepe/index 
TRUSS, C. et al. Soft and hard models of human resource management: a reappraisal. Journal of Management Studies, v. 34, n. 1, p. 53-73. 1997.

ULRICH, D. Os campeões de recursos humanos: inovando para obter os melhores resultados. São Paulo: Editora Futura, 1998.

VENTURA, V. L. S.; LEITE, N. R. P. Percepção da influência da gestão estratégica de pessoas no comprometimento organizacional. Revista Pretexto, v. 15, n. 3, p. 11-28, 2014.

WEI, L. Q. Strategic human resource management: determinants of fit. Research and Practice in Human Resource Management, v. 14, n. 2, p. 49-60, 2006.

WOOD, S. J. Getting the measure of the transformed high performance organization. British Journal of Industrial Relations, v. 37, n. 3, p. 391-417, 1999.

WOOD JR., T.; TONELLI, M. J.; COOKE, B. Colonização e neocolonização da gestão de recursos humanos no Brasil (1950-2010). Revista de Administração de Empresas, v. 51, n. 3, p. 232-243, 2011. 